\title{
INFRAESTRUCTURA Y SIGNIFICADO EN LA DOMINACIÓN INKA DEL CENTRO OESTE ARGENTINO (COA), EXTREMO AUSTRAL ORIENTAL DEL TAWANTINSUYU
}

\author{
Infrastructure and meaning in the Inka domination at the \\ Argentine central west (COA), oriental austral extreme of the \\ Tawantinsuyu
}

\author{
J. Roberto Bárcena* \\ Recibido el 12 de noviembre de 2007. Aceptado el 7 de enero de 2008.
}

En homenaje a mi muy querido amigo y maestro, Prof. Dr. Eduardo Ripoll Perelló

Resumen. Con el apoyo de la ANPCYT (SECYT) y del CONICET mediante subsidios, desarrollamos investigaciones arqueológicas y etnohistóricas sobre la dominación inka en el Centro oeste argentino, extremo austral oriental del Tawantinsuyu.

En la actualidad trabajamos en las provincias de La Rioja (Famatina, Laguna Brava, Guandacol, entre otras áreas), San Juan (Reserva de la Biosfera de San Guillermo, Valle Fértil, Paso del Lámar -Jáchal-, entre otros sectores) y Mendoza (Valle de Uspallata, Valle de Uco, entre otras zonas), estudiando la vialidad y los sitios relacionados, excavando varios de éstos.

Un abordaje de tal envergadura implica, entre otras, la posibilidad de contrastar semejanzas y diferencias en la implantación territorial, diversidad en las relaciones con las poblaciones locales y su manifestación en los indicadores arqueológicos y etnohistóricos y permite contrastar los modelos de dominación regional.

En este contexto nos referimos, desde la perspectiva del significado, al registro de bienes inka como ser, entre otros, la propia arquitectura o los relacionados con los sitios ceremoniales de altura.

Abstract. With the support of the ANPCYT(SECYT) and of the CONICET we have undertaken archaeological and ethnohistorical research on the Inka domination in the Argentine central west, at the oriental austral extreme of the Tawantinsuyu.

Our team is presently working in the provinces of: La Rioja (at Famatina, Laguna Brava, Guandacol, among other areas), San Juan (at the Reserva de la Biosfera de San Guillermo, Valle Fértil and Paso del Lámar -Jáchal-, among other sectors) and, Mendoza (at the Valle de Uspallata, Valle de Uco, among other zones), studying the net of roads and other related sites, excavating several of the later ones.

Such an approach implies, between others, the possibility of contrasting similarities and differences in the territorial implantation, the diversity in relations with the local inhabitants and its manifestation in the archaeological and ethnohistorical indicators, thus allowing for the contrast with the regional domination models.

From the perspective of the significance and within such a context, we refer to Inka goods such us the architecture in itself or those goods related to the high ceremonial sites.

(*) INCIHUSA-CONICET (Instituto de Ciencias Humanas, Sociales y Ambientales-Consejo Nacional de Investigaciones Cientificas y Técnicas; sede CRICYT-Mendoza).

UNCuyo (Facultad de Filosofía y Letras). E- mail: rbarcena@lab.cricyt.edu.ar.

Dirección: Casilla de correo 131, 5500 Mendoza, Argentina. Tel: 54-261-5244307.

(Dirijo los proyectos institucionales indicados, participando de los mismos: P. A. Cahiza, O. Di Giuseppe, J. García LI., N. B. Gorriz, S. E. Martín, L. A. Müller, M. Pannunzio de Mulle, M. J. Ots). 


\section{INTRODUCCIÓN}

El registro arqueológico de artefactos y arquitectónico del período Inka en el noroeste argentino (NOA) y en el centro oeste argentino (COA), como así el registro etnohistórico, refieren a un modelo de dominación que atiende variabilidades: hay diversidad regional significativa en la apropiación del espacio, según los recursos naturales, las condiciones ecológicas y demográficas, entre otros.

La imposición del modelo implica transformaciones en las etnias asimiladas, incluso ideológicas.

Asimismo, la copia de artefactos -cerámica, metalurgia, entre otros- de los modelos inka, entraña que adquieran nueva significación.

En algunos casos, como en los de la parafernalia relacionada con el culto solar y la fertilidad de la tierra en los santuarios de altura, que conlleva arquitectura, sacrificios rituales y artefactos escogidos, la condensación significativa alcanzó su máxima expresión.

Claramente regulados, según los datos del propio registro arqueológico y del etnohistórico, los sitios y las ceremonias de altura son producto de un conjunto de usos estatales habituales y ofrecen con los objetos que en ellas se emplean, como el caso de los tejidos, de las estatuillas votivas y de los adornos corporales, no sólo un característico icono inka sino también un contexto significativo, cuya decodificación implicaría reconocer mejor todo un lenguaje gráfico (Guaman Poma, 1936 -1613-; Blas Valera, 2007 -1618-).

Las apreciaciones precedentes se sostienen con la realidad de los registros dichos, como así por los planteamientos cada vez más concordantes de los especialistas de la temática inka, en general y del Kollasuyu en especial, particularmente de los colegas que han trabajado y trabajan en las vertientes oriental y occidental andina, en Argentina y en Chile.

Por refirmar con opiniones más conocidas y por ejemplo, Hyslop planteaba en su momento la variabilidad del registro arquitectónico inka (1990), expresando que "No two Inka State settlements are identical." para proseguir diciendo que "There were no universal principles followed in selecting a location and planning the layout of major inka settlements. Rather, a complex set of concepts was used, based on the major activities to be carried out in the settlements, its topography, the distance and amount of local labor, and local cultural influences.n (:306), concluyendo que "Major Inka settlements might be compared with fine Andean textiles, which served practical ends, but had much symbolism woven into them. As in weaving, the planning and layout of Inka settlements must have been a major intellectual, religious, and possibly aesthetic endeavor. It is clear that before designing a settlement, Inka architects had to be aware of a multitude of religious, political, economic, and ethnic factors before they could weave these influences into a coherent architectural layout.n (:309).
Mientras que Raffino, en su aporte sobre "El Shincal de Quimivil» (2004) y refiriéndose al NO argentino expresa que "Las discrepancias en los registros arquitectónicos y artefactuales indican que no puede hablarse de un modelo de dominio rígidamente extendido a todo el horizonte NOA. Existen significativas diversificaciones regionales en la apropiación del espacio por los Inka. Las que debieron depender de los recursos naturales, las condiciones ecológicas y el sustractum demográfico de cada territorion (:221), agregando, entre otros conceptos, que "Ciertos rasgos arquitectónicos en los sitios inkas están alternativamente sugiriendo prestigios o alternativas funcionales. Estos son las aukaipatas, collcas, ushnos, hornacinas, vanos (puertas y ventanas) trapezoidales; los altares con escalinatas de piedra; muros de piedras canteada, las jambas y dinteles" (: 224-225), como asimismo que "Los Inka no construyeron grandes poblaciones en el Kollasuyu, sino que se instalaron en sitios preexistentes", aunque, por otra parte, "construyeron sus centros administrativos en lugares donde no existían instalaciones locales» (: 223).

Opiniones que interesa aquí corroborar con las de Berenguer (et al) sobre la variabilidad provincial del Tawantinsuyu (2003) o bien de Williams (2000 -y D' Altroy y Williams, 1998-) sugiriendo esta última que el gobierno inka de los sectores australes en la práctica unió «control militar, reclamo ideológico, hospitalidad ceremonial, reubicación demográfica, tratamiento preferencial de algunos grupos étnicos e intensificación minera y agropastoril» (: 72), refirmando asimismo que algunas veces se tuvieron «en cuenta las variaciones locales en la organización social, los recursos y la historia de las relaciones políticas preexistentes.n, concluyendo que "como toda dominación, la inka trajo cambios en el uso y el significado de los espacios públicos, domésticos y ceremoniales de las sociedades locales" (: 73), volviendo finalmente sobre el hecho de que las "ocupaciones diferenciales" buscaban igualmente "la creación de paisajes inkaizados separados de las ocupaciones locales", haciéndolo como "un mecanismo de dominación planeado», persiguiendo «imponer la visión del mundo inka sobre las poblaciones dominadas, justificando su poder y autoridad e intentando reestructurar prácticas sociales» (: 74).

La diversidad en la unidad sobre la que venimos tratando admite otras hipótesis y corroboraciones más recientes, precisamente sobre el NOA, donde el estudio de un poblado del período prehispánico tardío (Tarragó y González, 2005) demuestra un prolongado "desarrollo local» y que fue "parcialmente ocupado y remodelado a partir de la dominación imperial en la región», apreciándose en este caso "variabilidad en los modos arquitectónicos incaicosı (: 129) habida cuenta que en el poblado se aprecian «técnicas constructivas incaicas limitadas a sectores seleccionados del asentamiento, manteniendo la estructura arquitectónica previa del sitio de génesis local.», agregándose que "El proceso de selección de los sectores, tanto aquellos de índole pública como pro- 
ductiva (agrícola y artesanal), no se basó únicamente en cuestiones prácticas sino que también tuvo en cuenta los contenidos simbólicos derivados de la circunscripción de determinados espacios» (: 141) para concluir que "tan importantes como las obras de infraestructura, las estrategias de dominación incluyeron la transformación imperial de los sistemas simbólicos, entre los cuales la concepción del espacio figuró entre los más trascendentes" (: 142).

En cuanto a la otra vertiente del abordaje de nuestro trabajo, referida a los sitios y ceremonias de altura, que remitimos prácticamente a la consideración de sólo uno de los casos de evidencias en altos cerros andinos del COA, implica asimismo variabilidad pero siempre en un contexto de «importancia en el registro arqueológico dada la concentración de rasgos y su significado en el marco institucional estatal incaico, sobre todo cuando se trata del hallazgo, como es el caso que abordamos, de un fardo funerario en uno de los contrafuertes del Cerro Aconcagua, y de las estatuillas ántropo y zoomorfas asociadas” (Bárcena, 2001: 158; 1989).

El hecho de abordar nuestra presentación en el marco del merecido homenaje a la memoria de don Eduardo Ripoll Perelló, implica que, luego de agradecer a sus organizadores por aceptar nuestra participación, nos orientemos principalmente al ámbito de nuestro propio registro arqueológico regional y al de las representaciones, con lo que entrañan de interpretación, pues esto es lo que conlleva el acto comunicacional, vinculando el objeto con el signo (semeion), y esto según los códigos que estructuran las relaciones signo-referente y emisor-receptor.

Sin pretender entonces con nuestro abordaje más que tener en cuenta nuestro registro y algunas consideraciones básicas sobre los signos, y sin afrontar un enfoque desde la teoría semiótica, nos abocaremos sólo a establecer algunos datos de las evidencias registradas relacionándolos con íconos y símbolos inka.

\section{ALGUNOS DATOS DE LOS REGISTROS ETNOHISTÓRICO Y ARQUEOLÓGICO DEL COA}

Conceptualmente ceñimos la Subárea arqueológica COA a determinados límites geográficos, que la realidad del proceso prehistórico regional nos obliga a traspasar una y otra vez. (Bárcena, 2002b -200-: 7 ss.) (fig. 1).

En rigor, sin embargo, la circunscribimos por el norte y el sur, respectivamente, con los ríos Jáchal-Zanjón (Prov. de San Juan) y Diamante (Prov. de Mendoza), haciéndola llegar por el oeste (Cordillera de los Andes) y el este (ríos Jáchal, Bermejo, Bajada de Ampacama, Desaguadero) casi hasta los límites actuales de las mencionadas provincias. Mientras que, también con ciertos grados de libertad en el planteamiento, relacionamos con el área circunscripta una determinada etnia protohistórica, la Huarpe, en conexión por el norte con la ampliamente denominada Diaguita, de habla cacana, proba- blemente representada por indígenas capayanes y yacampis, del Período tardío de la Etapa agroalfarera, sin descartar otros grupos étnicos de similares o disímiles características culturales. A la vez, relacionamos a los huarpes por el sur con etnias como la Puelche, de grupos de cazadores y recolectores, con alta movilidad territorial (Ibíd.).

Según este bosquejo elemental los indígenas de momentos prehispánicos tardíos del NOA, principalmente de las actuales provincias argentinas de Catamarca y La Rioja, sitas al norte de las nombradas del COA, son en sentido lato los diaguitas protohistóricos que ocupan con sus poblados, sementeras y sitios defensivos, entre otros, las áreas de valles y quebradas, que soportan una población relativamente numerosa, con medios de producción y uso espacial significativo, abarcando desde el manejo agropastoril al minero que les permitía sumar a sus artesanías de cerámica y de textiles, entre otras, la de metales preciosos y del bronce. Su organización sociopolítica, relativamente compleja según el área a que nos refiramos, alcanza la categoría de Jefaturas o Señoríos, notándose la existencia de grupos especializados en diversas tecnologías.

Entre esos grupos se aprecia, en lo que a su infraestructura arquitectónica se refiere, avances técnicos hacia el urbanismo, destacando sus conglomerados de instalaciones pircadas, como asi de paredes de barro y las mixtas de barro y piedra, propios de sus asentamientos en terrazas fluviales de fondos de valles y en las quebradas, coronados éstos, o no, por construcciones defensivas que dificultan la progresión en altura hacia los cerros próximos, baluartes, pucaras, funcionales a sus aparentemente recurrentes luchas por la frontera regional y también al interior de sus límites de expansión.

A su vez, los indígenas regionales Huarpes parecen ser relativamente menos numerosos, a la llegada de los inka (c. 1470 d. C.), que sus coetáneos del NOA, situación que se mantiene en la época prácticamente inmediata, cuando arriban los españoles (1551 d. C. en los valles de Caria y de Güentota). Esta etnia se encontraba en situación de aprovechar los valles irrigables principales de la región, como los del citado Caria o Tucuma, bañado por el río San Juan y sus afluentes, y el mencionado de Güentota o Cuyo, servido por el río Mendoza y sus tributarios.

Sin embargo, la principal etnia regional del COA participaba más bien de un patrón de instalación aldeano, con relativamente reducida concentración de viviendas de materiales perecederos, con toda probabilidad del tipo quincha, según grupos dispersos en el espacio, relacionados con cursos de agua, sean naturales, sean artificiales según tomas de vertientes, arroyos y ríos, y canalizaciones en acequias, con campos de cultivos próximos y todavía con una relativamente importante actividad de caza (camélidos, entre otros) y de recolección vegetal (de cierta enjundia ésta, habida cuenta del hecho de la existencia de algarrobales aprovechados de determinada manera por la etnia). 


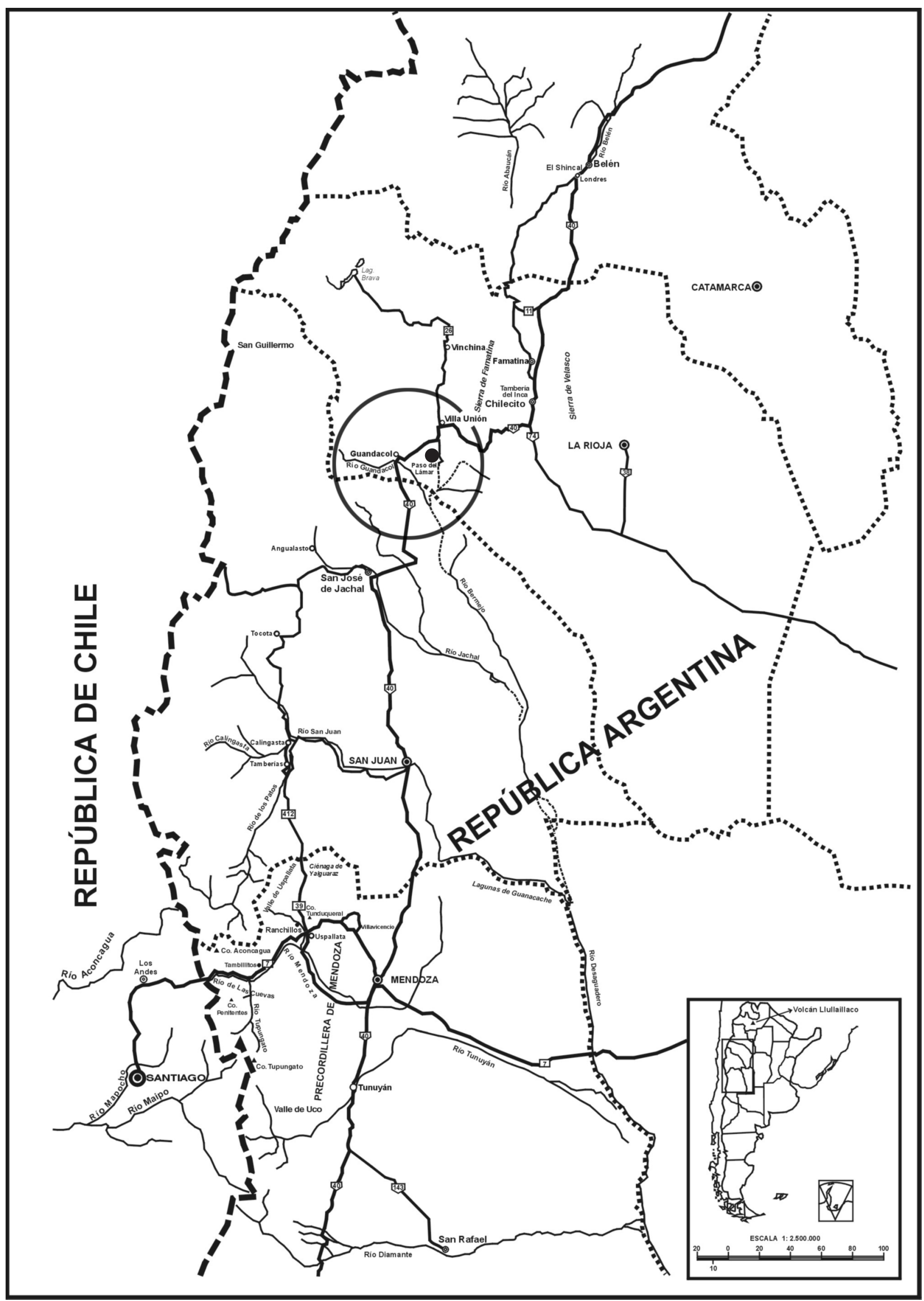

A FiguRa 1. En el mapa están registrados los principales topónimos referidos en el texto. 
Si bien está claro que los huarpes tenían una gama de divinidades tutelares, aparentemente sobresalía una, relacionada con los altos cerros, con la cordillera nevada, llamada Hunuc Huar. Sin embargo, no habría evidencias de ceremonias llevadas a cabo por huarpes en las alturas, aunque si hay menciones a su pensamiento sobre que los muertos moraban finalmente en esas sierras nevadas. (Canals Frau, 1942: 67 ss.; Michieli, 1983; Parisii, 2003). Por otra parte, sí hay datos etnohistóricos y arqueológicos sobre características de los entierros huarpes, que conllevan ajuares funerarios.

En cuanto a la organización sociopolítica huarpe se discute sobre si le corresponde asumirla en la categoría de las sociedades segmentarias, por referirnos a términos de una de las clasificaciones todavía en uso, o de las jefaturas, incluso señoríos. Aparentemente, a la llegada de los españoles se estaría transitando la etapa final del proceso que da paso a las jefaturas, existiendo numerosas referencias a "caciques" huarpes, e incluso, por lo menos a uno de ellos se lo consideró en época colonial hispana temprana, "Señor» del Valle de Güentota (Bárcena, 1994).

Tratándose de zonas áridas, en el COA es impensable el cultivo dependiente de las precipitaciones, obedeciendo la producción de alimentos vegetales a la irrigación, derivando para ella agua por canales y acequias, desde cursos o afloramientos hídricos naturales.

Esto implica desarrollo tecnológico local, que probablemente fue mejorado con la llegada inka. Tal hecho parece estar indicado, además de otro tipo de posibles inferencias sobre el dato, por la recurrente mención en los documentos hispánicos coloniales a las acequias del valle de Güentota, con nombres de "caciques" huarpes por ejemplo ("de Goaimaye»), y también las alusiones a la "toma del Inca" en el mismo valle o a "la acequia del Inga" en el valle de Caria. De igual modo, en varios casos las fuentes se refieren en el valle de Cuyo a la acequia o canal "Goazap Mayu», que parece reunir en la mención la referencia en quechua al curso hídrico, en este caso de traza artificial, junto con el nombre propio de un personaje, quizás en quechua, quizás en lengua local (Bárcena, 1994).

El sólo hecho de la doble denominación, como las citadas de Caria-Tucuma, Güentota-Cuyo, para esas áreas regionales, muestra claramente la resignificación toponímica, característica de la dinámica de la dominación inka regional.

Esta dupla nominativa, de lo local con lo quechua, introducido, no es única y se aprecia en sectores geográficos más restringidos, como es el caso Mauelturata-Uspallata, doble denominación indígena e inka de un valle de montaña del noroeste mendocino.

Ocurre lo propio más al sur de Güentota, área del Valle de Uco, cuyos pobladores, principalmente huarpes, sufrieron asimismo la dominación, que revistió características particulares a juzgar por su registro arqueológico y etnohistórico. Como se aprecia, la denominación Uco refiere a un término quechua, mientras que la denominación huarpe debió co- rresponder a alguna de las varias que conocemos para el sector en lengua local (Ibídem.).

La fuerza representativa, el código que alude al referente material de esos paisajes culturales de los valles de Caria y Güentota y más australes, adquiere el simbolismo buscado por la fuerza de la palabra introducida, de la lengua franca de entonces, el quechua, cuyo poder no desconocerán los nuevos conquistadores, hispánicos.

Éstos en sus primeros tiempos de dominio harán valer, asimismo según un juego simbólico, esas denominaciones precedentes de las áreas de sus conquistas y fundaciones de ciudades, de acuerdo con los intereses del momento, que buscan en parte la convalidación de su propio dominio, remitiendo a la toponimia estatal inka o a la local según conveniencia. Por último, primará en lo institucional hispánico colonial la denominación quechua Cuyo para lo regional y las hispánicas Mendoza y San Juan para lo local (lbíd.).

Por otra parte, las denominaciones quechua regionales no se limitan a lo esbozado, sino que abarcan numerosos iconos del paisaje, permaneciendo como topónimos clave de una época, como el nombre del majestuoso y más alto cerro andino, macizo del Aconcagua (alguna propuesta indica al origen del vocablo como aymara, lo que no invalida nuestro contraste), o el correspondiente a un arroyo desagüe, sito más allá del límite norte del conurbano de la ciudad de Mendoza, cuyo sugestivo nombre es Tulumaya, apelativo notable, muy propio del centro cuzqueño. (No sabemos cuándo se instaló esta denominación que, con la de chimba que está presente en Mendoza y San Juan, pudo también introducirse con los denominados yanaconas por los españoles de la fundación de Mendoza -1.561 d. C.-. "Yanaconas" que en algunos casos sumaban a su nombre castizo el apelativo «Inga»-lbídem).

Centrándonos en lo propiamente inka, con toda probabilidad los citados sean casos más que icónicos, simbólicos de alta relevancia, pues no sólo la re-significación alcanza el habla y al área, sino que revaloriza el ambiente, los paisajes, y los integra en el mapa estatal.

Por supuesto que el habla, que no abordamos más que de pasada aquí, registra también la nueva relación con el estado cuzqueño, como se aprecia en los vocabularios de la lengua huarpe. Éstos, en sus variantes allentiac -área de San Juan- y millcayac -área de Mendoza- (Valdivia, 1607, en Medina, 1894 y en Márquez Miranda, 1943), suman al padrón de lo local términos de origen quechua y aymara, que parecen haber estado en uso por los huarpes. (Aunque debemos reconocer que el Padre Luys de Valdivia escribe sobre los vocablos entre fines del siglo XVI y comienzos del XVII, haciendo el correspondiente relevamiento del habla entre los huarpes de la vertiente occidental de los Andes - llevados allí desde Cuyo/Tucuma por el servicio de encomiendas-). Este registro indica, por ejemplo, que los numerales por encima de la centena (tanto en el millcayac como en el allentiac) esta- 
blecen "pataca", palabra de origen aymara, para nombrar cien (Medina, 1894; Márquez Miranda, 1943; Bárcena, 1994).

La propia acepción "paredones del Ynga" o "paredones de izpallaja» (en este último caso y según nuestra opinión, en alusión al término Uspallata, que pudo ser a su vez el nombre de un funcionario inka), utilizada muchas veces en los documentos españoles tempranos de la ciudad de Mendoza, refiere sin duda a una construcción paradigmática inka, sobresaliente con respecto a las seguramente elementales construcciones aldeanas huarpes, a juzgar por lo que sabemos de éstas por los registros etnohistórico y arqueológico con que contamos en Mendoza (Bárcena, 1994).

Esta mención a un sitio inka del valle de Güentota, con su particular alusión de lo arquitectónico, la hemos tratado, entre otras, en nuestra citada publicación de 1994, y ahora nos facilita introducirnos en las evidencias de tal indole registradas en el COA.

Datos sobre el registro arquitectónico regional inka

En efecto, el registro arqueológico de la presencia inka regional incluye, junto con otras categorias de infraestructura, los tambos - con diverso grado de jerarquía en la organización estatal de la región y por tanto con funcionalidades específicas-, al menos un pucara y varios sitios ceremoniales de altura (que involucran o no capacochas). Se trata de tipos de instalaciones que en su mayoría están vinculadas con trazas visibles de la red vial.

Al analizar estas instalaciones, especialmente la infraestructura de los genéricamente denominados tambos, hallamos que si los comparamos en su conjunto, considerándolos desde el centro de la actual provincia argentina de Catamarca (NOA), pasando por las de La Rioja y San Juan, hasta alcanzar la de Mendoza -límite austral oriental de la organización estatal- (COA), ofrecen diferencias apreciables, como por ejemplo en la superficie abarcada por las construcciones delimitadas por muros -sean de piedra, de otros materiales, o mixtos- y en los tipos de las edificaciones presentes -además de su calidad, envergadura y detalles constructivos-.

Sin embargo, y en general, cualquier tambo suma a la evidencia de los artefactos característicos del período, sean obtenidos por prospecciones superficiales o en profundidad por excavaciones, su relación de proximidad con la vía inka

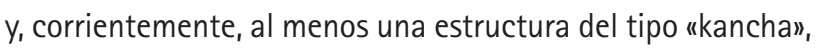
"Rectángulo Perimetral Compuesto» ("RPC॥), denominada así según una de las clasificaciones en uso (Madrazo y Otonello, 1966; Raffino, 1982, 1991:112 ss.).

Sólo este hecho introduce una impronta en la planificación arquitectónica de los asentamientos que, con distinto grado de certeza, marca una diferencia constructiva con las instalaciones autóctonas coetáneas.
Si bien en el caso de las instalaciones del NOA puede decirse que los conglomerados edilicios del Período de los Desarrollos Regionales (referido a los momentos prehispánicos tardíos, que por otra denominación se consideran propios del Período Prehispánico Tardío o Período tardío de la Etapa agroalfarera) no respondieron en general a una planificación urbana y que incluso su crecimiento no la siguió -salvo contadas excepciones-, puede hablarse a la vez y por ejemplo sobre la existencia en esos establecimientos, conformados por estructuras pircadas o construidas con otras materias primas diferentes a la piedra, de edificaciones habitacionales con patio, de espacios abiertos como plazas, de calzadas, de escalinatas y rampas, de basurales, de cementerios, entre otros, que son preexistentes a la llegada inka y que implican claramente elementos urbanisticos.

Mientras que, hasta donde sabemos y salvadas en cierta medida las conspicuas instalaciones de Guandacol (La Rioja) y de Angualasto (San Juan), conformadas principalmente por materiales arcillosos, puede decirse que desde el extremo sur y norte, respectivamente, de esas provincias hasta el río Diamante en Mendoza, que es prácticamente la extensión del COA, no se han registrado instalaciones de enjundia, sea en materiales pétreos, arcillosos o mixtos, que admitan paralelos con las coetáneas, conspicuas del referido período del NOA, con excepción, precisamente, de varias de las instalaciones propias de la subsiguiente dominación estatal inka.

De manera tal que lo arquitectónico inka del NOA significa la implantación planificada y según un patrón distintivo de los establecimientos, que suman a estas nuevas condiciones de la arquitectura regional, su fuerza de la representación simbólica del dominio estatal sobre el de jefaturas preexistente.

Sin duda el característico patrón de instalaciones inka, con su red vial, más allá de la funcionalidad y de los símbolos arquitectónicos del poder, implica nuevos códigos para las poblaciones locales: reelaboración de los propios con los implantados, según una neta influencia, en parte incentivada por los lenguajes visuales de los dominadores.

No sólo la planificación urbana, al estilo de los «nuevos Cuzco", denota la novedosa situación, sino que hacen lo propio componentes característicos, como las aukaipatas, kallankas, ushnus, cerros ceremoniales con escalinatas, collcas, entre otros, como así, particularidades de las construcciones como los hastiales, las hornacinas y los vanos trapezoidales, entre otros. Y esas formas, componentes arquitectónicos, que en general no tenían tradición regional, a diferencia de lo que ocurría en los Andes «nucleares», también dieron su impronta a las "protociudades" preexistentes, cuya modificación y sobre imposición de un nuevo planeamiento bajo dominio inka, han sido señalados por Raffino con respecto a las del NOA de los Desarrollos Regionales (1991: 204).

No arroja dudas el carácter pragmático de la sobre imposición por los inka de la traza de usu clásico planeamiento en damero regularizado de la Kancha» en las «protociudades exis- 
tentes" del NOA, al decir de Raffino (Ibídem), como asimismo no podemos abrigarlas sobre su significación y claro simbolismo, como así sobre su expresión de un lenguaje visual propio.

Por contraste, podemos volver sobre las ya aludidas superficies construidas de buena parte de los tambos del COA, comparándolas entre sí y con dos de las más conspicuas instalaciones inka del NOA de Catamarca y La Rioja, establecimientos de El Shincal de Quimivil (74.180 m²; "Nuevo Cuzco" del área de Belén, próxima al pueblo de Londres, en el sector valliserrano de Catamarca; Raffino, 2004) y de la Tambería del Inca $\left(12.812,49 \mathrm{~m}^{2}\right.$, instalación de envergadura, circunscripta por un muro, propia del área de Chilecito, junto a la ciudad riojana homónima; Greslebin, 1940), para constatar cómo estas implantaciones inka "puras" reflejan, por su envergadura y tipos de componentes arquitectónicos, claramente los sectores geográficos de mayor interés para la organización estatal, los que, además de sus posibilidades económicas, implicarian áreas con relativamente apreciable densidad de población, sumándose por lo tanto a la estrategia del aprovechamiento espacial según determinados fines, la de establecer íconos referenciales del poder estatal, principalmente en los sectores más conspicuos de presencia de las poblaciones locales.

Según los guarismos de la Tabla I, que presentamos en escala logarítmica, las dos instalaciones mencionadas destacan del resto, y no sólo por las cifras de superficie construida, sino asimismo por los tipos y calidad constructiva de sus componentes arquitectónicos, siguiéndoles la de Paso del Lámar $\left(9.328,12 \mathrm{~m}^{2}\right)$, sita en el sector noreste extremo de la provincia de San Juan, junto al río Bermejo, en una posición próxima a la de los asentamientos de la población lo- cal, cuya densidad demográfica debió ser apreciable a juzgar por las evidencias derivadas de nuestras investigaciones del extenso yacimiento aledaño, que denominamos Las Juntas y corresponde al Período de los Desarrollos Regionales.

El establecimiento inka de Paso del Lámar, que según nuestros estudios fue abandonado antes de completarse su construcción, probablemente a causa del arribo hispánico, consiste en el característico planeamiento de un tambo de envergadura, con sus RPC, plaza intramuros, planta de una kallanka, entre otros. A lo dicho se suma un cerro bajo con escalinata -con toda probabilidad ceremonial- y un sector en terraza, a mayor altura, que alberga construcciones escogidas, alrededor de otra aukaipata. Estas construcciones parecen culminar en un ushnu, estando delimitado el conjunto por muros bajos y coronado por un alto cerro conexo, cuyo ascenso dificultan estructuras defensivas pircadas, conformándose un típico pucara, inka desde su origen, a juzgar por nuestras excavaciones junto a muretes, en recintos y en parapetos del mismo (Bárcena, 2002a, 2005).

El camino inka, con dirección norte-sur, atraviesa el tambo, haciéndolo por el lado oeste de la aukaipata de su sector más bajo (Ibídem).

El conjunto edilicio, al que se suma una relativamente extensa área próxima, con vertientes e indicios de prácticas agrícolas, es hasta la actualidad el de mayor envergadura conocido en el COA (ubica prácticamente en el límite noreste extremo de la Subárea arqueológica) y está constituido como adelantamos por tipos arquitectónicos característicos de los establecimientos relevantes inka (salvando la escala, por ejemplo El Shincal tiene asimismo aukaipatas, ushnu, ka-

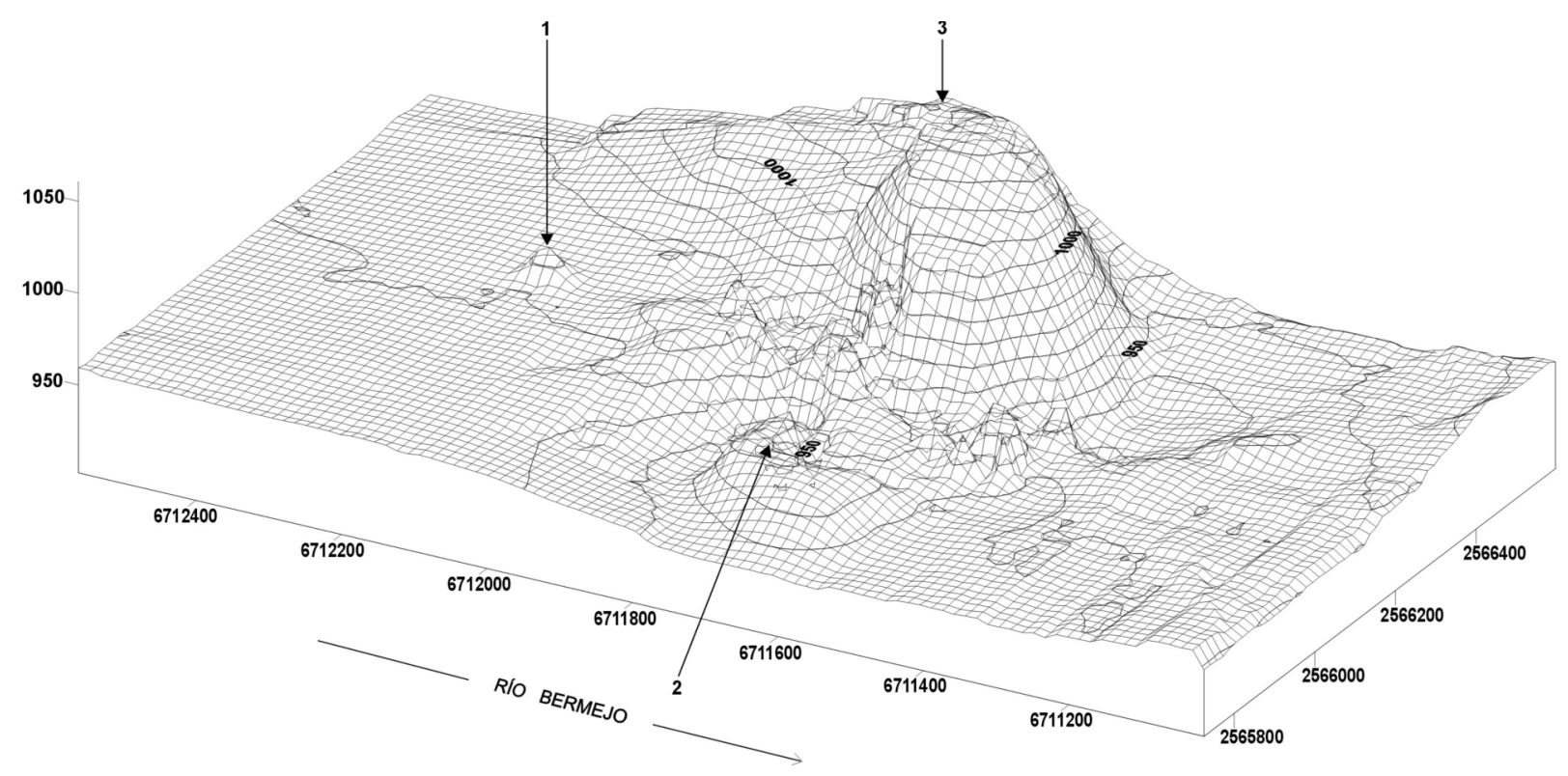

- Figura 2. a) Croquis del relieve del área de la Tamberia de Paso del Lámar y de la arquitectura (estructuras de paredes de pitas: recintos, escalinatas y muros ( b. página siguiente) del sitio. Los números 1, 2 y 3 de ambos croquis indican lo mismo: el cerrito con escalinata en el sector de la terraza de la margen izquierda del río Bermejo, la zona de otro nivel en terraza por encima del anterior y el área del pucará. 


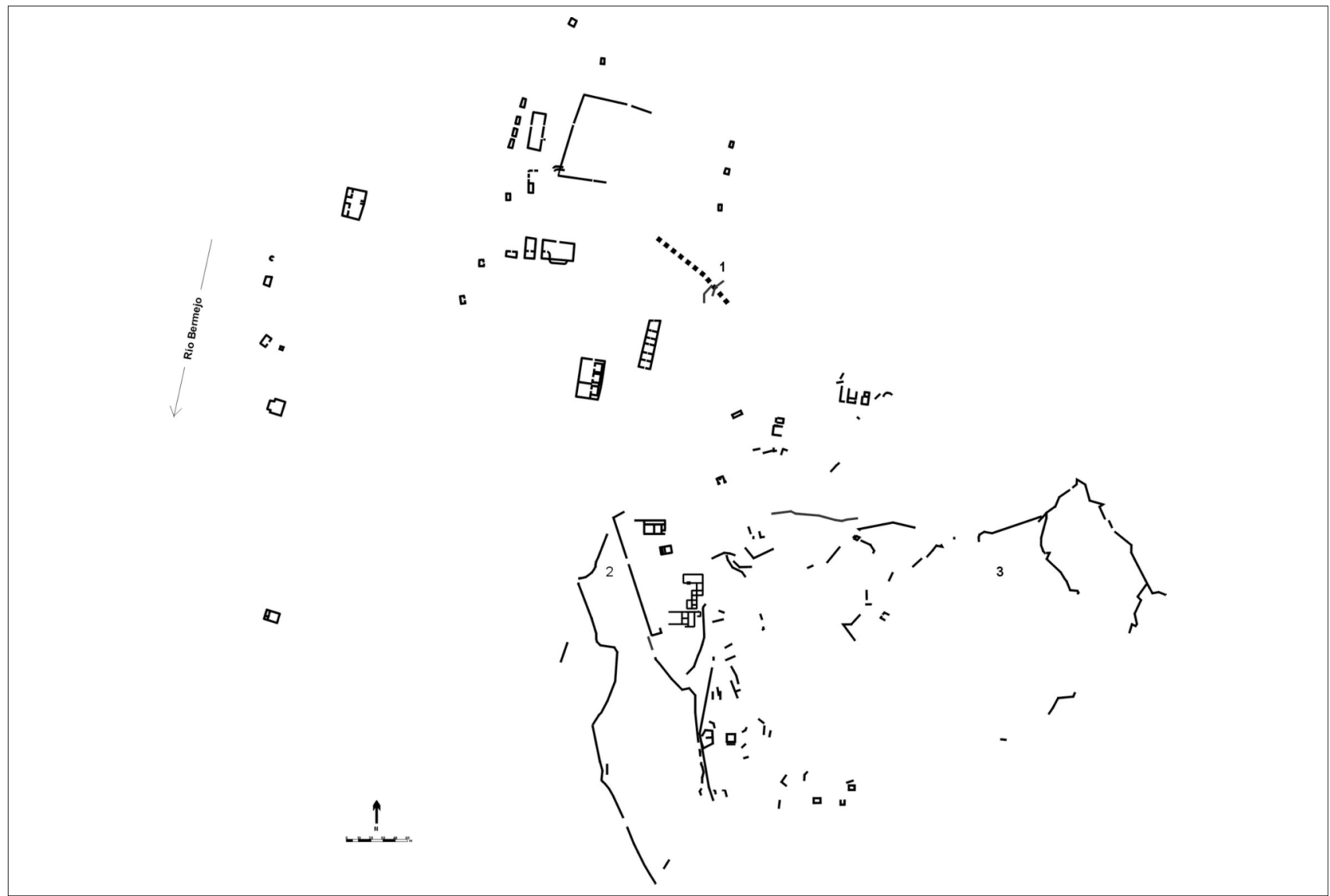

A Figura 2b

Ilankas, cerro ceremonial con escalinata, entre otros elementos relevantes -Raffino, 2004-). Asimismo, a diferencia de la mayoría de los sitios inka, Paso del Lámar cuenta con un pucara, que es el más austral conocido, implantado por la organización estatal en su progresión al COA, área ésta que será finalmente el extremo austral oriental del Tawantinsuyu, límite que alcanzan y se hallan consolidando muy poco antes del arribo hispánico (fig. 2).

El caso de Paso del Lámar es paradigmático de la organización estatal, pues a la habilidad de establecer un importante asentamiento en tierras bajas (c. 1.000 m.s.m), con probables fines de avanzar por el río Bermejo hacia las todavía más bajas (c. 500 m.s.m) y estratégicas tierras de la confluencia con los ríos Mendoza y San Juan, área lagunera de ecología y poblaciones particulares, suman consolidar el foco de la población autóctona en la propia posición de la convergencia de los ríos Bermejo y Guandacol, en Paso del Lámar, previniéndose con un pucara, a la vez que re-significando el paisaje cultural con sus íconos arquitectónicos representativos del poder político y religioso estatal, en marcado contraste con las instalaciones de materiales de- leznables, diseminadas en áreas de cultivo, propias de la población local de Las Juntas y próximas².

Más al sur, en el corazón del COA, como se aprecia en la citada Tabla I, las instalaciones inka son ya de menor envergadura, excepción hecha de la más austral y oriental conocida, la de Ranchillos, en el valle de Uspallata del noroeste mendocino. Se trata de un conspicuo tambo, "Tambo real de Ranchillos", con las caracteristicas "kanchas" y plaza intramuros, cuya superficie construida alcanza los $6.648 \mathrm{~m}^{2}$ y que por comparación con los relevantes casos tratados, sólo detenta algunos atributos salientes, como por ejemplo los revoques de barro, muros y vanos característicos, y un posible hastial en su "RPC" más notable (Aparicio, 1940; Rusconi, 1956; Bárcena, 1998b) (Tabla I).

Justamente, la relativa excepcionalidad de Ranchillos deviene en absoluta cuando analizamos la infraestructura de instalaciones inka del COA -tambos, sitios ceremoniales de altura, red vial-, en contraste con la propia de las poblaciones locales, encontrándonos con que lo arquitectónico inka regional deviene por si en icono, en significativa representación de la dominación local y regional por la organización estatal.

(2) Nuestra campaña arqueológica de 2006 en Paso del Lámar permitió determinar que algunas estructuras pircadas, ubicadas fuera del espacio del característico planeamiento inka, en el sector sur oriental del sitio, ofrecen materiales cerámicos de una ocupación anterior a la inka y a la época de los Desarrollos Regionales. Éstos los hemos datado en el siglo VII d.C.: en forma relativa por su tipología y en forma absoluta (14C) merced al carbón de los fogones de las correspondientes asociaciones y contextos. 


\section{TABLAI}

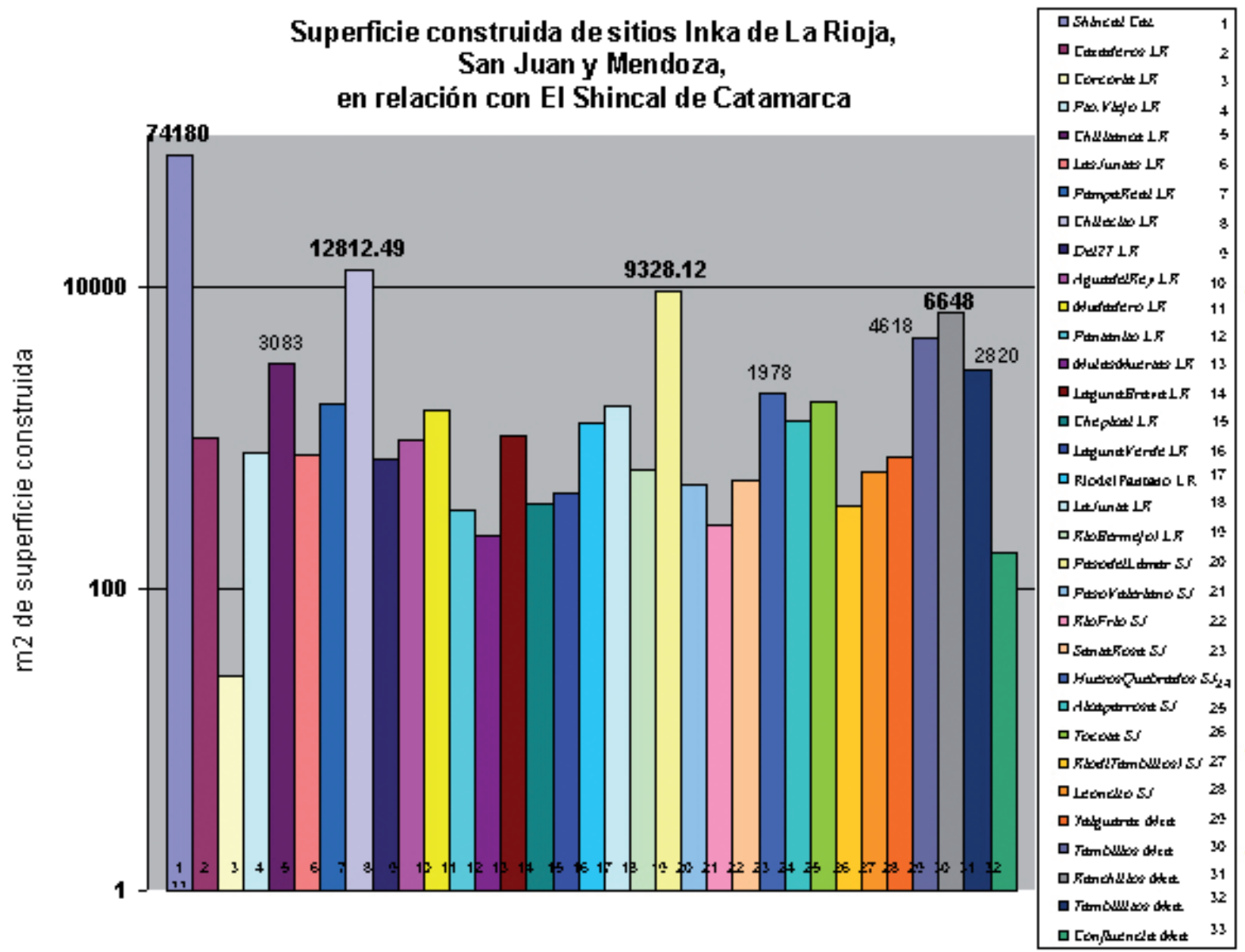

Datos de los registros arqueológico y etnohistórico de los sitios ceremoniales inka de altura

En este orden de representaciones simbólicas deseamos referirnos también, aunque en forma escueta, a los sitios ceremoniales inka de altura, particularmente al que concierne al Cerro Aconcagua, del noroeste extremo de la Provincia de Mendoza.

Como sabemos, es notable el número de elevados cerros andinos que presentan vestigios que refieren a la presencia inka y que han llevado a inferir que se trata de sitios ceremoniales, santuarios de altura.

Éstos están situados en las propias cumbres o en lugares próximos, por ambas vertientes de la divisoria de aguas internacional, en los casos que se trate de cerros limitrofes entre Argentina y Chile, o bien están ubicados en cordones al interior de ambos países, por referirnos al sector del Área Meridional Andina donde se ha reconocido la mayor cantidad de sitios.

Si bien el aserto precedente puede deberse, entre otros, a la prolongada por décadas y prácticamente continua acción de an- dinistas y estudiosos, es decir de la necesaria convergencia de la práctica montañista con la investigación científica y que en gran medida tuvo lugar en nuestras regiones; es por otra parte innegable que se debe a su vez a la realidad de un uso ritual sistemático de los Andes meridionales por los inka. (Ver entre otros: Schobinger, 1966, 1986; Beorchia Nigris, 1987-1984-; 2001 dirección y coordinación; Vitry, 1996, 2000; Schobinger y Ceruti, 2001; Ceruti, 1999, 2003; Bárcena, 1989, 2001).

Esta re-significación simbólica de las alturas andinas, a su vez cargadas de connotaciones religiosas para las poblaciones regionales, ofrece otro claro caso de reorientación significativa hacia el ordenamiento estatal, según nítidos lenguajes visuales del inka, sea por el hecho mismo del sitio ceremonial, los dones y fuerzas sobrenaturales allí invocadas, sea por las señales emergentes del lugar, como la posible visibilidad de combustiones en la cima, sobre las que se ha inferido muchas veces y sobre las que podemos al menos contrastar los vestigios que dejarian, de los cuales tenemos evidencias por los carbones que tapizan determinadas estructuras. ${ }^{3}$

(3) V.g.: Cerro Penitentes de la Cordillera Frontal del NO de Mendoza; cuya densidad de carbones en el relleno de la principal estructura, sita a 4.300 msm, en la cima del cerro, nos permitió datar la asociación, por $\mathrm{C}^{14}$ en el siglo XV d.C. comprobando a la vez la excelente visibilidad del lugar: hacia el distante $C^{0}$ Tupungato, hacia la más próxima quebrada del río de Las Cuevas-Mendoza, lugar del paso del camino inka a la vertiente occidental andina y de los sitios asociados, tambos conexos al camino; mientras que, asimismo a la distancia, se aprecia desde esa altura y con nitidez la posición de los sitios de Confluencia -3.300 msm, tambillo en la aproximación al sitio ceremonial de La Pirámide del Aconcagua- y la del citado contrafuerte del $\mathrm{C}$ Aconcagua, lugar del santuario aludido -5.300 msm- Asimismo, comprobamos que la trilogía de sitios, Cerro Penitentes-Confluencia-Pirámide, pueden además ser unidos por una línea virtual, lo que agrega una condición particular del manejo espacial inka. 

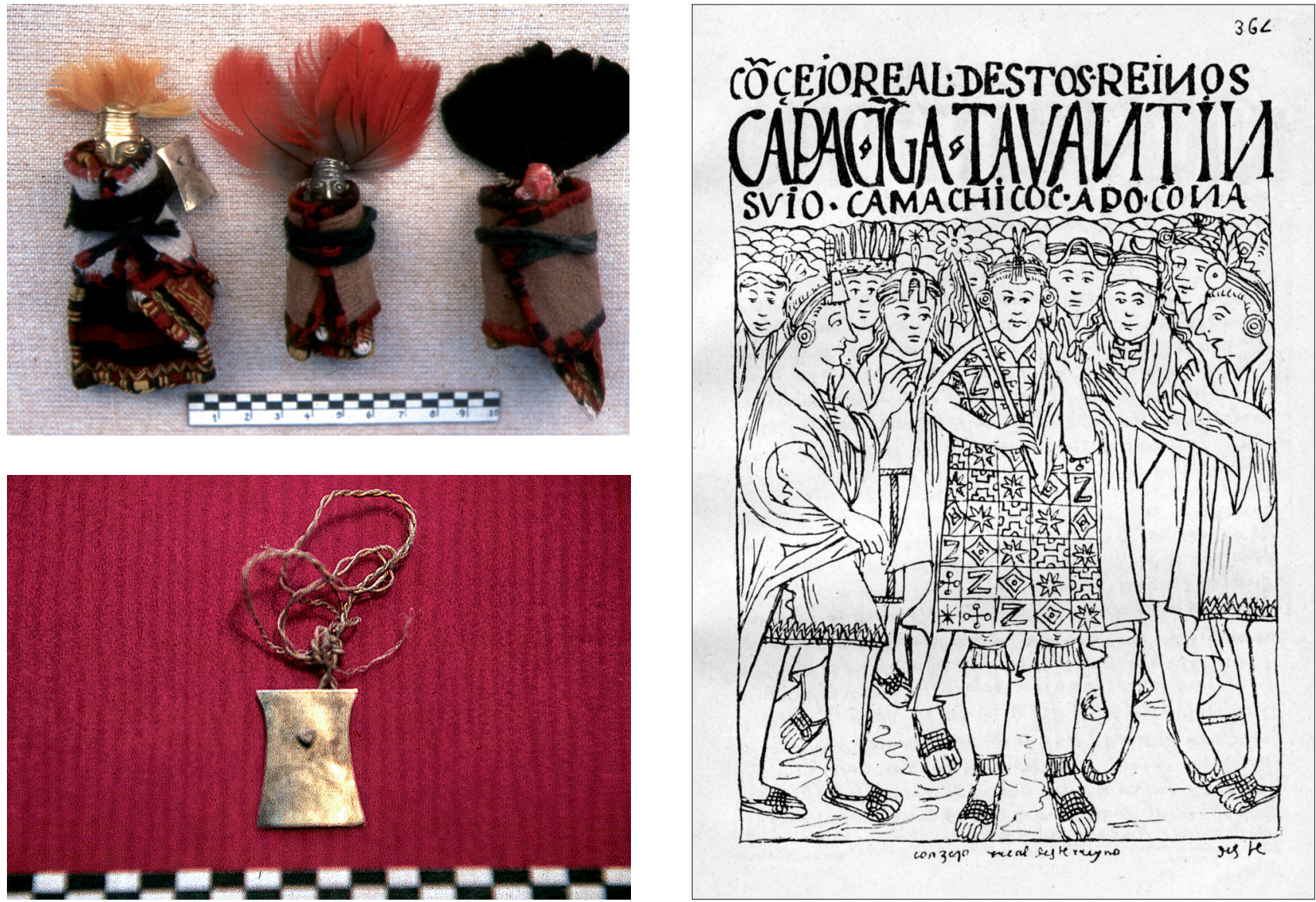

- Figura 3a. Se advierten las estatuillas antropomorfas del sitio ceremonial de altura del Co Aconcagua. Son masculinas y se aprecian vestidas. La confeccionada en oro laminado, sita a la izquierda, muestra la plaquita, también de oro laminado, colgando en la posición que tenía en la estatuilla, al ser hallada ésta junto al fardo funerario. Asimismo, en las restantes imágenes se observan por una parte la referida pequeña lámina, recortada según la característica forma trapezoidal y horadada para fungir colgante, y por la otra el dibujo atribuido a Guaman Poma sobre el "Consejo Real ...", donde se aprecia un elemento similar a la referida placa, como atributo de las máximas autoridades de la organización estatal inka. (Fotografías J.R. Bárcena).

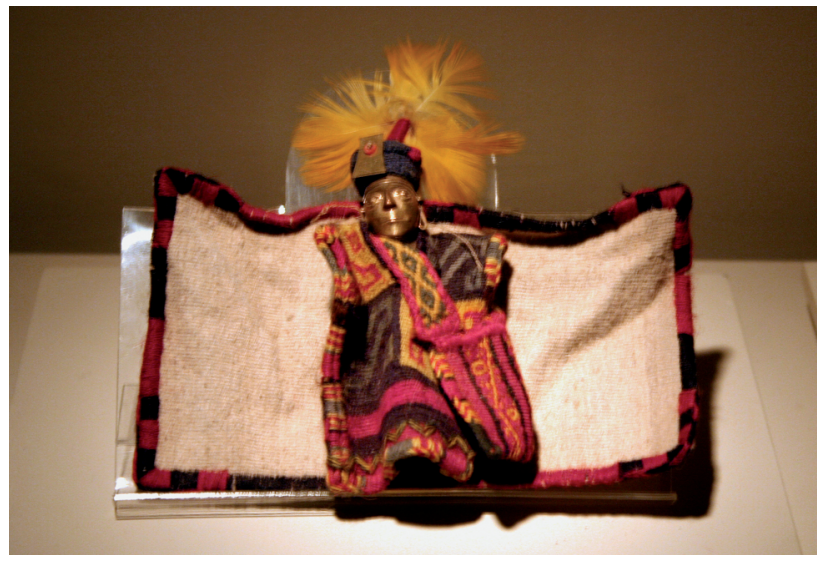

A Figura 3b. La estatuilla S-17 del santuario del Co Llullaillaco, con el manto o yacolla desplegado. Se aprecia el penacho de plumas amarillas, el uncu o camiseta andina, la bolsa o chuspa y, según interesa destacar aquí, el llautu y la pequeña placa trapezoidal incorporada al mismo, tal como se los apreciaba en la exposición del Museo de Arqueología de Alta Montaña (Salta), en octubre de 2007. (Fotografía J.R. Bárcena).
Semejante fuerza ideológica e inversión de recursos, tecnológicos y económicos, implica alcanzar objetivos rituales de una religión estructurada, doctrina del Tawantinsuyu inseparable del avance político estatal, que se apropia asimismo de los espacios sagrados y los re-significa a su uso, con la parafernalia, esta sí seguramente más visible para muchos, de las comitivas y procesiones en pos de los santuarios.

No fue poca cosa seguramente, integrar al sistema el cerro más alto de los Andes (el Aconcagua tiene una altura de $6962 \mathrm{msm}$ ), aunque se lo hiciera ritualmente por uno de sus contrafuertes, como no pasó desapercibida tampoco su más nítida percepción desde la vertiente occidental andina, área del Valle de Aconcagua en sentido lato.

A poco que indaguemos no sólo la evidencia arqueológica inka del actual lado chileno de los Andes, sino mejor la de la documentación etnohistórica del área, hallamos una rica relación de la época colonial temprana, que parece aludir a lo que planteamos, incorporando específicamente conceptos religiosos del centro peruano, como las referencias a Pachacamac, entre otras (Bárcena, 1989; Stehberg y Sotomayor, 2005). 
No pueden abrigarse dudas por lo tanto sobre los nuevos significados, contenidos simbólicos del paisaje, producto de la incidencia, con la perspectiva de la organización estatal, sobre entidades de por sí sacras para las poblaciones locales.

Sin embargo, la conexión simbólica iría más allá, como una vez sugerimos, pues la posición geográfica de los cerros elegidos para las capacocha del extremo sur andino, como el Aconcagua argentino y El Plomo chileno (Mostny, 1957; Cabeza, 1986), refieren entierros de niños vestidos a la usanza y con objetos simbólicos, del Chinchaysuyu (Aconcagua) y del Kollasuyu (El Plomo), que parecen reeditar en los confines los aspectos del fraccionamiento cuatripartito y bipartito (Hanan, Hurin). (Bárcena, 1989; 2001).

En este sentido, es útil contrastar asimismo los sitios ceremoniales y hallazgos conspicuos en dos sectores alejados entre sí y característicos de los Andes: el mencionado de la capacocha del Aconcagua (Provincia de Mendoza, Argentina) y el de las capacochas del Volcán Llullaillaco (Provincia de Salta, Argentina).

Con esto nos encontramos con que sobre similares bases doctrinales estatales, y según los casos, se ha incrementado diferencialmente la inversión. Apreciamos una mayor incidencia sobre el paisaje cultural y mucha mayor abundancia y calidad de los dones sacros, en el más tempranamente dominado y más central sector andino, representación significativa del Volcán Llullaillaco; mientras que, con respecto al sector al que se accede más tardíamente, sito ya en la periferia de un dominio no sólo a punto de fenecer, sino que se va agostando en su modelo con los límites poblacionales y ambientales, comprobamos asimismo una fuerte representación simbólica, aunque relativamente menguada en la parafernalia de altura, como es el caso de la propia del Cerro Aconcagua y en general de los sitios de los altos cerros del COA.

Sin extender más estas consideraciones, que para el caso del Llullaillaco pueden seguirse, entre otros, en los trabajos de Ceruti (2003), y para el del Aconcagua, entre otros, en los propios de Schobinger y su compilación de un esfuerzo colectivo al respecto (2001), ofrecemos a continuación una semblanza de este último sitio y de los hallazgos en el mismo, siguiendo nuestra propia contribución al tema e interpretaciones que estimamos adecuadas al fin perseguido en nuestro artículo, sumando algunas nuevas consideraciones, a partir de registros más recientes (Bárcena, 1989, 2001, 2007 a y b).

En efecto, deciamos oportunamente que el hallazgo en uno de los flancos del Cerro Aconcagua, sitio señalado con pirca prehistórica, correspondió a un fardo funerario acompañado de seis estatuillas, confeccionadas en metales preciosos -oro, plata- y en "mullu», las que eran antropomorfas masculinas - tres- y estaban vestidas con "uncu», "yacolla" sujeta por un cordón y "chuspa», que en un par de casos tenían fragmentos de hojas de coca en su interior. Estas estatuillas estaban coronadas por un penacho de plumas -en cada caso de distinto color - y las referidas mantas eran de parecidos o de distintos colores, mientras que las camisetas andinas y las bolsas coqueras, también de lanas de colores, albergaban tocapus.

Las otras tres estatuillas representaban camélidos machos, confeccionados en láminas de oro, en un caso, y en la valva Spondylus en los restantes.

Entre las estatuillas antropomorfas de metal -son dos, maciza de plata una, en láminas de oro la otra (la tercera está confeccionada en la concha del molusco marino)-, destaca la de oro laminado, con penacho de plumas amarillas y sobre cuyas vestimentas pendía de un cordón una pequeña lámina, también de oro, trapezoidal y horadada para dejar pasar ese cordón de sujeción (Bárcena, 1989; 2001; 2004).

Elementos como bolsas con contenidos de origen vegetal y sandalias, entre otros, acompañaban el fardo o estaban en él -incluso se reconoció una pequeña lámina de oro enrollada sobre sí misma-. Justamente, el desenfardado mostró una estructuración compleja del mismo, con múltiples telas, incluso alguna de ellas con decoraciones conspicuas, hasta alcanzar el cuerpo de un niño de siete u ocho años al que cubrían. Éste, vestía uncus, colocados de una determinada manera, al igual que calzaba ushutas y portaba en su lugar un collar de piedras semi-preciosas. (Para una visión amplia de todo el conjunto y sus interpretaciones, ver Schobinger, 2001 -compilador-, o bien nuestros trabajos recién citados, entre otros).

Además de lo someramente descrito, nos llamó la atención un pigmento de color rojo, que había manchado las envolturas y vestimentas y que, lo más notable, correspondía al unto, de apariencia oleosa, del cuerpo.

Asimismo, apreciamos una sustancia del mismo color que embadurnaba los dientes y que la autopsia controlada del cuerpo demostró que también se hallaba en el primer tramo del aparato digestivo y en el último.

Lo dicho señala otra notable característica de esta capacocha, que es la de cubrir el cuerpo con una sustancia y, según nuestras investigaciones, usar la misma para su ingestión por el niño.

Determinamos el pigmento como proveniente del urucu 0 achiote (Bixa orellana), con el que se había realizado el unto $y$, también según nuestra opinión, las ingestiones con fines del ayuno ritual (Bárcena, 1989).

La cantidad de atributos y la complejidad simbólica de esta capacocha es tal que además, y entre otros, habíamos señalado que la estatuilla de su ajuar, antropomorfa masculina de oro, que portaba una plaquita trapezoidal del mismo metal (Bárcena, 2001: 285-286, 296; 2004: 160-162), lo hacía al estilo de la similar ostentada en el llautu por los más altos funcionarios que rodeaban al inka, como se aprecia en dibujos atribuidos a Guaman Poma de Ayala, como es el caso del titulado "Consejo Real de estos reinos..." (1936 1613-: 364; ver para otra opinión sobre la autoría de estas ilustraciones, entre otros, Laurencich Minelli, 2006) (fig. 3a). 

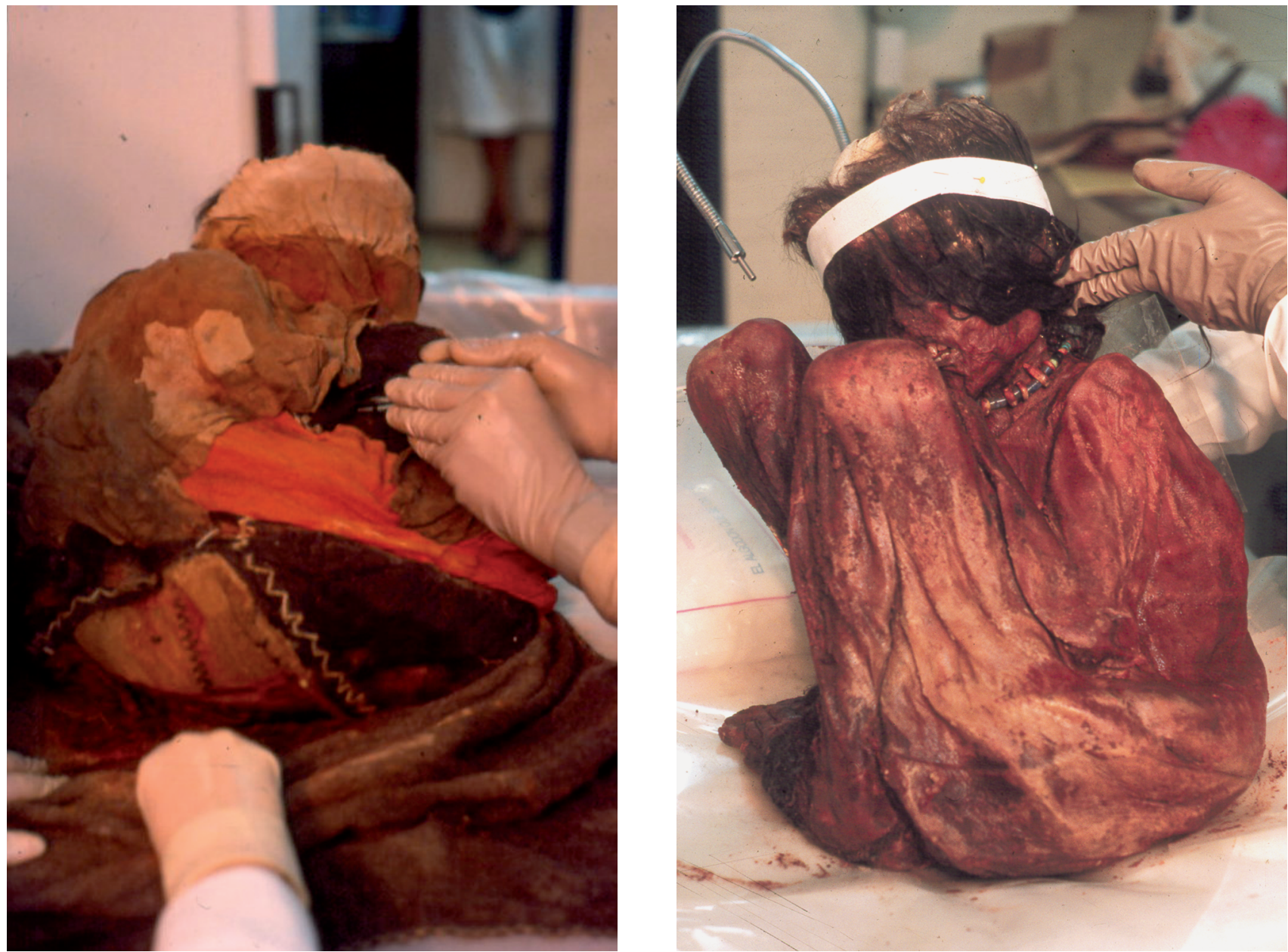

- Figura 4. Ímágenes del fardo funerario y del cuerpo "embijado", luego del desenfardado, de la capacocha del santuario del Co

Aconcagua. Las ilustraciones corresponden a las tareas de laboratorio, apreciándose la complejidad de los textiles que cubrian al niño y la propia preparación de éste, con el unto rojo y conservando todavía el calzado y un significativo collar (la banda en la cabeza fue colocada por nosotros para preservar la integridad de sus cabellos). (Fotografías J.R. Bárcena).

Atributos del tipo de la placa trapezoidal, son señalados también, para seguir con el ejemplo elegido, como propios de algunas de las estatuillas de las ofrendas del Co Llullaillaco, como puede verse en Ceruti (2003).

En efecto, y hasta donde pudimos discernirlo en el citado trabajo, hay tres estatuillas antropomorfas masculinas, confeccionadas en la valva Spondylus ("mullu"), que suman el "adorno" trapezoidal de oro o de plata, tienen penacho de plumas amarillas o rosas, y que se corresponden con la capacocha representada por la momia infantil masculina, haIlada en la llamada Tumba Sur (Ibíd.: 73). En rigor, dos de las estatuillas combinan penacho amarillo con placa de oro, mientras la tercera lo hace con penacho rosa y placa de plata (Ibíd.: 221-222, Lámina 5: S-25, S-18, S-40).

En otros tres casos, de los seis registrados que portan estas placas, se trata también de estatuillas antropomorfas masculinas, que están confeccionadas en oro y provienen de entierros de ofrendas denominados $S B, S A$ y NE (Ibíd.: 228-229, Láminas: 3 -S-17- y 5 -S-10, NE-7-), teniendo dos de ellas el penacho trabajado con plumas rosas o bien naranjas y las respectivas plaquitas elaboradas en plata (fig. 3b).

Como se aprecia, tanto en la única capacocha del Aconcagua, infantil masculina, como en la infantil masculina de la múltiple capacocha del Llullaillaco, el ajuar de estatuillas, que son antropomorfas masculinas, cuenta con atributos de penachos amarillos con placas de oro, o bien para el segundo caso citado, de plumas rosas o naranjas en correspondencia con placas de plata, demostrando las comparaciones un estándar de representación, pero sobre todo una incidencia significativa de atributos de poder de la máxima jerarquía inka en los dos sitios: en relación proporcional con la inversión ceremonial invertida en cada uno.

Estas no son coincidencias que puedan establecerse entre todos los sitios inka de altos cerros andinos, con capacocha o sin ella, con lo que la representatividad ceremonial religiosa o bien la jerarquía en la escala de la organización estatal podría estar indicada, además de la inversión económica y según la representatividad ceremonial, por atributos conspicuos como los señalados. 

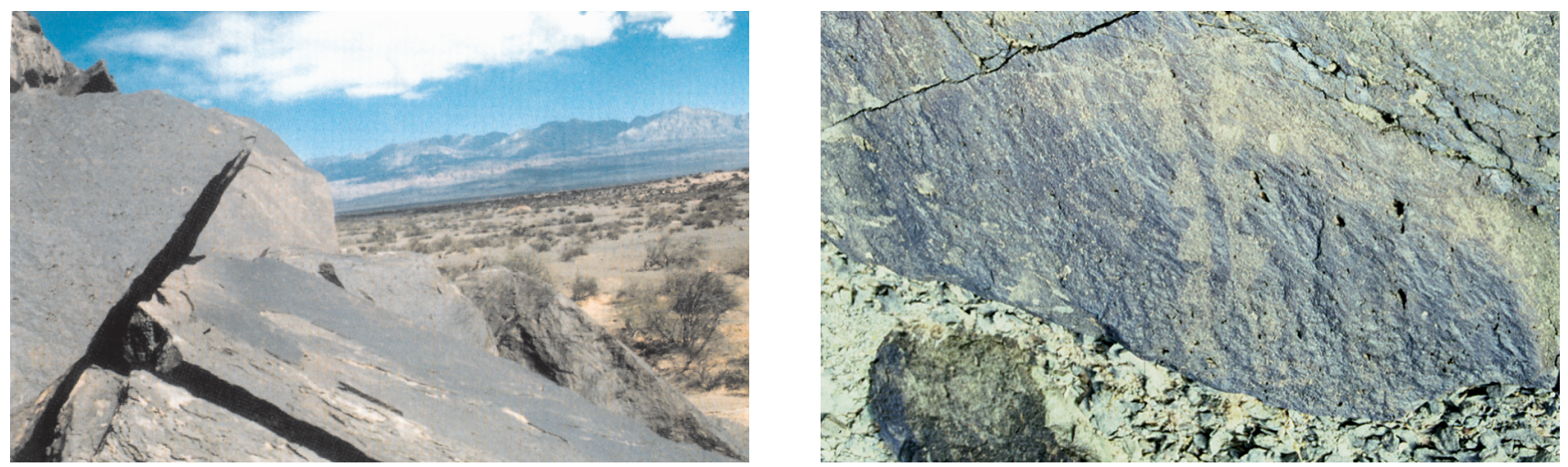

- Figuras 5 a) Zona con grabados rupestres, sita al suroeste de la tambería de Paso del Lámar. Los grabados se han relacionado con diferentes periodos prehispánicos, incluso el inkaico; b) Algunos de los motivos podrían corresponderse con otros que se aprecian en la decoración pintada de la cerámica propia de la etapa tardía local de la etapa agroalfarera prehispánica (cultura arqueológica de Sanagasta/Angualasto). (Fotografías R. Bárcena).

Sobre bases como las esbozadas someramente hasta aqui, habíamos concluido hace años con respecto al simbolismo de la capacocha del Aconcagua, resumiéndolo en términos como los que siguen.

Decíamos entonces, que los lugares ceremoniales enclavados en altos cerros, por encima de los $4.300 \mathrm{~m}$ en nuestra área, adquieren importancia en el registro arqueológico dada la concentración de rasgos y su significado en el marco institucional estatal incaico, sobre todo cuando se trata del hallazgo de un fardo funerario en uno de los contrafuertes del Cerro Aconcagua, y de las estatuillas antropo y zoomorfas asociadas.

La peculiaridad del mismo, un sacrificio ritual humano en una "huaca" de altura -"santuario de altura"-, y de la ceremonia cuyos vestigios reputamos relevantes para la interpretación contextual, nos permiten avanzar explicaciones más allá de las concernientes a la época y marco global cultural de la ofrenda -incaicos-, y de la apreciación del significado general de ésta.

Es así como inscribimos los trabajos en una línea concordante con nuestra hipótesis sobre la procedencia - 0 "representatividad"- del sacrificio y respecto del marco socio-político-religioso de la ceremonia en la organización estatal incaica.

Fundamos nuestro estudio entonces en que estábamos en presencia de una capacocha con fuertes indicios de su procedencia costeña peruana - etnías de la costa central o sur de ese país-, o que por lo menos la intencionalidad de la misma fue dicha representación, que la misma aludía a la máxima jerarquía de la organización estatal, o a situaciones conexas con ella, y que en relación con la ideología política y religiosa implícita, debíamos considerarla en términos Chinchaysuyo-Hanan Cuzco, si se desea, "derecha", "arriba" y "masculino", y, también, con alguna relación con el ritual de Pachacamac.

Surge así con fuerza la importancia de algunos señoríos costeños y su persistencia durante la dominación incaica, co- mo también la preeminencia del culto de Pachacamac y su asociación con el estatal, propia del sincretismo religioso imperante.

Agua, tierra, peces y aves, multiplicación humana, piscícola, agrícola y ganadera, parecen ser los componentes cúlticos de esta especie de importante sincretismo en un no menos majestuoso Cerro Aconcagua.

El culto de Pachacamac - dios de los sismos, entre otros atributos-y asociados, y el impuesto por el Estado, parecen reunidos en un único acto del Aconcagua, bajo la regulación de la más alta jerarquía del Tawantinsuyu.

El repaso muestra también la importancia del color rojo en los rituales prehistóricos, su persistencia y cómo puede relacionárselo con ceremonias principales, de máxima jerarquía, en el incario. Además, se suma el hecho de que un señorío costeño derivaría su nombre del color rojo y que este pigmento, cualquiera fuera la sustancia de origen, revestía un carácter sagrado, asociado al culto de Pachacamac.

Datos del «embalsamamiento" de los Incas o sobre el "embijamiento" en ceremonias que los tienen por protagonistas, implicarían el unto rojo (Fig. 4).

Una parte de las ceremonias, en especial las relacionadas con "penitencias" y urogativas", conllevan "ayunos rituales" y la práctica de "purgas" con determinadas sustancias, administradas por la boca y el ano.

Se advierte una intencionalidad de preservación de una parte de las ofrendas, en particular de las capacocha.

Entendemos que está presente aquí la idea de conservación, básica en la momificación, por lo que interpretamos la conjunción «limpieza» del conducto digestivo preservación por un unto-congelamiento como una técnica particular de la misma, en este específico marco ritual.

Con esta perspectiva, entonces, sugerimos que para este tipo de capacocha de altura sería suficiente alcanzar los niveles de montaña con congelamiento perpetuo, para depositar la ofrenda (Bárcena, 1989: 104-105; 2001: 158-160). 


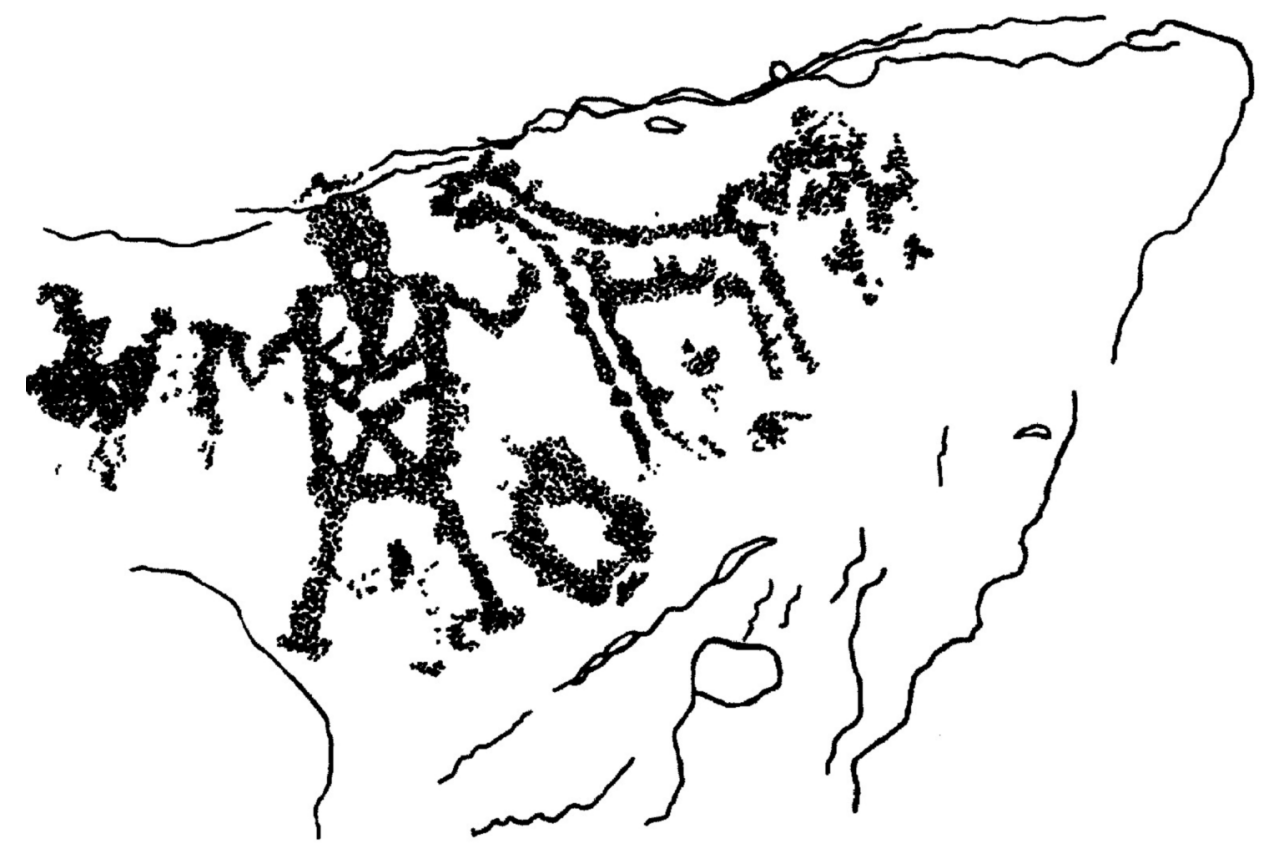

A Figuras 6. Grabado rupestre del Ca Tunduqueral, Valle de Uspallata, NO de Mendoza. Representa prácticamente la única escena del sitio $y$, a diferencia de la mayoría de los petroglifos del mismo, pudo corresponder a momentos prehispánicos tardíos, probablemente en relación con escenas de la época, propias, entre otros, del tránsito por el cercano camino inka. (Relevamiento rupestre nuestro).

Datos del registro de las representaciones rupestres

En orden al simbolismo imperante, y aunque sea someramente, no deseamos dejar de mencionar aquí otro de los temas significativos, como es el que concierne a las representaciones rupestres, que en ciertos sitios y en alguna medida se han considerado como improntas inka sobre rocas que a la vez acusan grabados preexistentes, del Período de los Desarrollos Regionales, entre otros.

Por ejemplo, parece ser el caso de los grabados existentes en un sector de una formación rocosa muy próxima al mencionado sitio de Paso del Lámar -NE de San Juan-, que representan motivos propios de las poblaciones de momentos tardíos prehispánicos, y anteriores, con los que se relacionan otros, que han sido interpretados como inka. (Schobinger, 1966; Bárcena, 2002a, 2005), con lo que parece sumarse también en las representaciones rupestres la re-significación de las mismas por los dominadores (fig. 5).

Sin embargo, más relevante nos parecen algunos casos donde apreciamos el registro rupestre de aspectos de la dominación inka, según la interpretación de los mismos por las poblaciones locales que acusan el impacto dominador.

Es el caso particular, notable, de las representaciones rupestres que alberga el Cerro Tunduqueral (Schobinger, 1982), en el sector central del Valle de Uspallata o Mauelturata (NO de Mendoza) (Bárcena, 1994), que a los grabados geométricos, zoomorfos y antropomorfos, entre otros, propios de poblaciones del Formativo local de hace unos mil años, suman, en la parte más alta del cerro, desde donde se podia apreciar el tránsito por el no tan lejano camino inka, una representación naturalista, que constituye prácticamente la única "escenan del lugar y que reúne a un camélido, aparentemente con dogal, con un personaje ataviado con camiseta andina cruzada en diagonal por dos líneas que parten de cada lado de la prenda, en representación característica del tránsito observable, propio del Período de los Desarrollos Regionales, y en este caso, bajo dominio inka (Bárcena, 2002b: 54) (fig. 6).

Es decir que es probable que esta diferente representación no sólo implique un tiempo más tardío de las poblaciones prehispánicas del área indicada, sino la visión de las mismas en su ambiente netamente simbólico sobre la particular injerencia territorial que soportan por el avance inka.

\section{A MODO DE CONCLUSIONES}

De la exposición precedente nos parece que al menos podemos concluir que:

- La dominación inka atiende variabilidades regionales, acusadas en los registros arquitectónicos y de los artefactos.

- La variabilidad regional depende, entre otros, de los recursos naturales a disposición, de las condiciones ecológicas y de la base demográfica.

- Parece incidir asimismo la distancia del centro y la cronología del avance.

- La variabilidad implica adaptabilidad que les hace refuncionalizar áreas y establecimientos preexistentes. 
- De esto queda un claro registro, con representaciones de prestigio, jerárquicas y funcionales, que incluso perduran en tiempos coloniales (el propio registro documental da cuenta de esto).

- Sin embargo, en el COA, con excepción quizás de Guandacol, no se han registrado establecimientos preexistentes que fueran modificados por los inka.

- De igual modo, no se registran instalaciones defensivas como pucara, con excepción de Paso del Lámar : ubicado en un sitio uni-componente inka, parece estar relacionado con una frontera de riesgo. Aparentemente es el pucara más austral del sistema.

- En este contexto son altamente significativas las representaciones simbólicas de los santuarios de altura, con sus asociaciones espaciales y la parafernalia de los sitios, donde destaca con los dones icónicos la figuración ceremonial de las jerarquias estatales.

- De igual modo, son significativas las representaciones rupestres de la época de los desarrollos regionales o bien del período Tardío de la etapa agro-alfarera, que involucran más directamente a las poblaciones locales de las áreas incididas por el dominio inka.

- Asimismo, son casos más que icónicos, simbólicos de alta relevancia, los propios de la re-significación del habla y toponímica de los territorios, que revaloriza el ambiente, los paisajes, y los integra en el mapa estatal.

- Qhapaq Ñan y tambos son claros signos regionales del dominio, cuya representatividad y significación es más notable en el $\mathrm{COA}$, especialmente en la parte más austral del mismo.

- El propio Qhapaq Ñan adquiere mayor significación en contextos ceremoniales.

En este sentido, los tipos y los atributos arquitectónicos inka de jerarquía-prestigio decrecen cuanto más al sur avanzamos: desde el centro de San Juan al NO de Mendoza, por ejemplo, no se registran kallankas, ushnos, cerritos ceremoniales con escalinatas, collcas, hallándose, con reparos en algunos casos, hastiales, vanos trapezoidales -jambas y dinteles-, hornacinas y enlucidos de barro.

Si bien el modelo de planeamiento de los establecimientos inka reconoce la estandarización de un patrón urbano imperial y determinada geometria de la distribución y plantas, acusa diferencias regionales, aunque éstas a su vez, como al menos en el caso de las instalaciones del NO de Mendoza, representan un patrón homogéneo.

\section{BIBLIOGRAFÍA}

Aparicio, Francisco de. (1940): Ranchillos. Tambo del inca en el camino a Chile. Anales del Instituto de Etnografía Americana, I, pp. 245253. UNCuyo. Mendoza. Ilustr.

BÁRCENA, J. ROBERTO.1979 (1977): Informe sobre recientes investigaciones arqueológicas en el N.O. de la Provincia de Mendoza - Argentina (Valle de Uspallata y zonas vecinas) (Con especial referencia al período incaico). Actas del VII Congreso de Arqueología de Chile, vol. II, pp. 661-692. Ediciones Kultrun. Santiago de Chile, 1979. 1 mapa. 4 figs. 2 láminas.

BÁRCENA, J. ROBERTO. (1988): Investigación de la dominación incaica en Mendoza. El tambo de Tambillos, la vialidad anexa y los altos cerros cercanos. Espacio, Tiempo y Forma, Serie I, Prehistoria, t. I, pp. 397-426. UNED. Madrid. 10 figs.

BÁrcena, J. Roberto. (1989): Pigmentos en el ritual de la momia del Co Aconcagua (Provincia de Mendoza, República Argentina). Separata de "Xama", 2, pp. 61-116. Publicación de la Unidad de Antropología. Área de Ciencias Humanas. CONICET. CRICYT-Me. Ilustr.

BÁRCENA, J. ROBERTO. 1994 (1991/92): Datos e interpretación del registro documental sobre la dominación incaica en Cuyo. Xama, 4-5, pp. 11-49. Publicación de la Unidad de Antropología. Area de Ciencias Humanas. CRICYT. Mendoza. 5 figs.

BÁRCENA, J. ROBERTo. (1998 a): Arqueología de Mendoza. Las dataciones absolutas y sus alcances. EDIUNC. Mendoza. 414 pp., 71 ilustr., 20 gráficos, numerosos cuadros.

Bárcena, J. Roberto. (1998 b): El Tambo de Real de Ranchillos. Mendoza, Argentina. Xama, 6-11, pp. 1-52. Publicación de la Unidad de Antropología. Area de Ciencias Humanas. CRICYT. Mendoza. 34 figs., 7 cuadros, 9 gráficos, 4 tablas.

BÁrCENA, J. ROBERTO. (2001): Estudios sobre el santuario incaico del cerro Aconcagua. Separata de cuatro capítulos del libro "El santuario incaico del cerro Aconcagua", EDIUNC, compilado por J. Schobinger. Los capítulos son sobre "Pigmentos en el ritual funerario...", pp. 117-170, "Los objetos metálicos de la ofrenda ritual...", pp. 281-301, "El collar de la momia...", pp. 302-331 y "La infraestructura arquitectónica incaica...", pp. 361-375. UNCuyo, Mendoza. Ilustr. 126 pp.

BÁrCena, J. Roberto. (2002a): Perspectivas de los estudios sobre la dominación inka en el extremo austral-oriental del Kollasuyu. Boletín de Arqueología PUCP, no 6, pp. 277-300. Lima. Ilustr.

BÁrCenA, J. Roberto. (2002b): Prehistoria del Centro-Oeste argentino. (Separata). (En: E.E. Berberián y A.E.Nielsen -comp.-, Historia Argentina Prehispánica, tomo II, cap. 3, pp. 561-634. Editorial Brujas. Córdoba. 2001). Unidad de Antropología, INCIHUSA-CONICET. CRICYT-Me. Ilustr. 80 pp. 2001.

BÁRCENA, J. ROBERTO. (2004): Las piezas metálicas de la ofrenda ritual del Cerro Aconcagua. Mendoza, República Argentina. ANEJOS DE AESPA, XXXII, pp. 157-172 (Tecnología del oro antiguo: Europa y América). CSIC. Madrid. Ilustr.

BÁrCenA, J. RoberTo. (2005): Avances 2002-2003 sobre el conocimiento arqueológico y etnohistórico de la dominación inka en el CentroOeste argentino, extremo austral oriental del Tawantinsuyu. Xama, 15-18, pp. 119.149. Publicación de la Unidad de Antropología. INCIHUSA-CONICET. CRICYT. Mendoza. Ilustr.

BÁRCENA, J. ROBERTO. (2007a): Arqueología de la arquitectura inka del Centro oeste argentino. Actas del XVII Congreso de Arqueología Chilena. Valdivia. En prensa.

BÁRCENA, J. ROBERTO. (2007b): Avances 2005/2007 sobre Arqueología y Etnohistoria de la dominación inka del Centro Oeste Argentino: arquitectura y vialidad en La Rioja, San Juan y Mendoza. Actas del XVI Congreso Nacional de Arqueología Argentina, tomo II: 493499. Jujuy.

BEORCHIA NigRIS, ANTONIO. 1987 (1984): El enigma de los santuarios indígenas de alta montaña. "Revista del CIADAM", tomo 5, año 1984. Centro de Investigaciones Arqueológicas de Alta Montaña. San Juan. Ilustr. 414 pp. + ilustr.

BEORCHIA NIGRIS, ANTONIO (Dirección y Coordinación). 2001 (1987-1999): Revista del C.I.A.D.A.M., tomo $6^{\circ}$. Centro de Investigaciones Arqueológicas de Alta Montaña. San Juan. Ilustr. 326 pp. 
Berenguer, José, Nielsen, Axel, Cáceres, Iván y Hernández, Pedro. (2003): El Inkañan en el Alto Loa y su relación con el Altiplano de Lípez. "Resúmenes", pp. 18. Simposio ARQ-8 Tawantinsuyu 2003: avances recientes en Arqueología y Etnohistoria. 51 ${ }^{\circ} \mathrm{CIA}$. Santiago de Chile.

CabezA Monteira, Angel. (1986): El santuario de altura inca Cerro El Plomo. Tesis de grado para optar al título de Licenciado en Antropología y Prehistoria de Chile. Departamento de Antropología. Universidad de Chile. Santiago de Chile. Ilustr. 256 pp.

Cahiza, Pablo. (2001): Problemas y Perspectivas en el estudio de la Dominación Inca en las Tierras Bajas de Mendoza y San Juan: El Sitio Torre 285, Retamito. Xama, 12-14 : 173-197.

Canals Frau, Salvador. (1942): Tres estudios de Etnología de Cuyo. Librería García Santos. Mendoza. 131 pp. + ilustr.

Ceruti, María Constanza. (1999): Cumbres sagradas del Noroeste argentino. Avances en Arqueología de alta montaña y etnoarqueología de santuarios de altura andinos. EUDEBA. Buenos Aires. Ilustr. 205 pp.

Ceruti, María Constanza. (2003): Llullaillaco. Sacrificios y ofrendas en un santuario inca de alta montaña. Instituto de Investigaciones de Alta Montaña. Universidad Católica de Salta. Salta. Ilustr. 347 pp.

De LA FueNTE, NicolÁs R. (1973): El yacimiento arqueológico de Guandacol, Provincia de La Rioja. Revista del Instituto de Antropología, IV: 151-167. FFyH. UNC. Córdoba. Ilustr.

García, E. Alejandro. (2006): La ocupación indígena tardía del sur de San Juan y su relación con la dominación incaica: el área de Acequión. XX Jornadas de Investigación, Resúmenes, p. 378-379. UNCuyo. Mendoza.

GrESLEBIN, HÉCTOR. (1940): Arqueografía de la Tambería del Inca (Chilecito, La Rioja, República Argentina). J. Rosselli \&t Cía. Buenos Aires. Ilustr. $27 \mathrm{pp}$.

Guaman Poma de Ayala. 1936 -1613-. Nueva Corónica y Buen Gobierno (Codex péruvien illustré). Institut d' Ethnologie. Université de París. Travaux et mémoires de I'Institut d'Ethnologie, XXIII.

Hierro S. Pescador, José. (1984) (2ª . Edición): Principios de Filosofía del Lenguaje. 1. Teoría de los Signos, Teoria de la Gramática, Epistemología del lenguaje. Alianza Editorial Textos. Madrid. Ilustr. 189 pp.

HYSLOP, JOHN. (1990). Inka Settlement Planning. University of Texas Press. Austin, Texas. Ilustr. 377 pp. Ilustr.

Laurencich Minelui, Laura. (2006): Dos documentos jesuíticos silenciados: los documentos Miccinelli. En: Manuel Casado Arboniés y otros (Editores), Escrituras silenciadas en la época de Cervantes, pp. 165-196. Universidad de Alcalá. Alcalá de Henares. Ilustr.

Madrazo, Guillermo y M. Otonello. (1966): Tipos de instalación prehispánica en la región de la Puna y su borde. Monografías, $n^{\circ} 1$, Museo Municipal Dámaso Arce. Olavaria. Ilustr.

Márouez Miranda, Fernando. (1943): (Ver Valdivia, P. Luys de)

MEDINA, José TORIBIO. (1894): (Ver Valdivia, P. Luys de).

MiCHIELI, C.TERESA. (1983): Los huarpes protohistóricos. Instituto de Investigaciones Arqueológicas y Museo. San Juan. 215 pp.

Mostny, GRete (Editora). (1957): La momia del cerro El Plomo. "Boletín del Museo Nacional de Historia Natural", tomo XXVII, n 1. Santiago de Chile. Ilustr. 118 pp. + ilustr.

OTS, MARÍA JosÉ. (2007): La presencia incaica en el Valle de Uco, Mendoza. Tesis doctoral. Facultad de Filosofía y Letras. UNCuyo. Mendoza. Ms. 286 pp. + Apéndice. Ilustr.

PARISII, MónICA. (2003): Dominación incaica en Mendoza. Allubgraf. Mendoza. 160 pp.

Raviña, María G. y Callegari, Adriana B. 1988. Mapa arqueológico de la Provincia de La Rioja. Revista del Museo de La Plata, Nueva Serie, tomo IX, Antropología n 67, pp. 21-92. FCNYM. UNLaPlata. La Plata. 1 mapa, 2 cuadros.

Raffino, Rodolfo A. 1982. Los Inkas del Kollasuyu. Ramos Americana Editora. La Plata. Buenos Aires. Ilustr. 301 pp.

Raffino, Rodolfo A. 1991. Poblaciones Indigenas en Argentina. Urbanismo y proceso social precolombino. TEA. Buenos Aires. Ilustr. 272 $\mathrm{pp}$.

Raffino, Rodolfo A. 2004. El Shincal de Quimivil. Editorial Sarquis. Catamarca. Ilustr. $272 \mathrm{pp}$.

RusCONI, CARLOS. 1956. La ciudadela prehispánica de Ranchillos (Mendoza). Revista del Museo de Historia Natural de Mendoza, IX (1-2), pp. 55-87. Mendoza. Ilustr.

SCHOBINGER, JUAN. 1966. Investigaciones arqueológicas en la Sierra de Famatina (Prov. La Rioja). Anales de Arqueología y Etnología, tomo XXI, pp. 139-196. FFyL. UNCuyo. Mendoza. 41 figuras, 1 cuadro.

SCHOBInger, JUAN. 1982. Los petroglifos del Cerro Tunduqueral, Uspallata, Provincia de Mendoza, República Argentina. Ars Praehistorica, tomo I, pp. 123-139. Editorial AUSA. Barcelona. Ilustr.

SCHOBINGER, JUAN. 1986. La red de santuarios de alta montaña en el Contisuyo y el Collasuyo. Evaluación general y problemas interpretativos. Comechingonia, año 4, número especial, pp. 295-317. Córdoba. 11 figuras.

SCHOBInger, JUAN (Compilador). 2001. El santuario incaico del cerro Aconcagua. EDIUNC. Mendoza.

Schobinger, Juan y María Constanza Ceruti. 2001. Arqueología de alta montaña en los andes argentinos. En: E.E. Berberián y A.E.Nielsen -comp.-, Historia Argentina Prehispánica, tomo II, cap. 2, pp. 523559. Editorial Brujas. Córdoba. Ilustr.

Stehberg, RubÉn y Gonzalo SOTOMAYOR. 2005. Cultos inkaicos en el Valle de Aconcagua (Chile Central). Xama, 15-18, pp. 279-285. Publicación de la Unidad de Antropología. INCIHUSA-CONICET. CRICYT. Mendoza.

VALDIVIA, P. LUYS DE. 1607. Arte y Gramática en dos Lenguas de Indios Millcayac y Allentiac... , Vocabulario breve en Lengua Millcayac... Lima. En: F. Márquez Miranda, "Los textos Millcayac del P.Luys de Valdivia..." Revista del Museo de La Plata (Nueva Serie), t. II, Sección Antropología, pp. 61-223 + VI lám. La Plata, 1943.

VALDIVIA, LUYS DE. 1607. Doctrina Cristiana y catecismo con un confesionario, arte y vocabulario breves en Lengua Allentiac. "Reimpreso todo à plana y renglón, con una reseña de la vida y obras del autor por José Toribio Medina". Imp. de E. Rasco. Sevilla. 1894.

Valera, Blas 2007 (1618). Exsul Immeritus Blas Valera Populo Suo. Edición de L. Laurencich Minelli , "Exsul Immeritus Blas Valera Populo Suo e Historia et Rudimenta Linguae Piruanorum". CLUEB. Bologna. 590 pp.

Vitry, Christian. 1996. Arqueología de alta montaña de la provincia de Salta. Ms.

VitRY, Christian. 2000 (2da. Edición). El Nevado de Cachi. Gofica Editora. Salta. Ilustr. $128 \mathrm{pp}$.

Tarragó, Myriam N. y LuIS R. GonzÁlez. 2005. Variabilidad en los modos arquitectónicos incaicos. Un caso de estudio en el Valle de Yocavil (Noroeste argentino). Chungara, vol. 37, n 2, julio-diciembre 2005, pp. 129-143. Universidad de Tarapacá. Arica. Ilustr.

Williams, VerónicA I. 2000. El imperio Inka en la provincia de Catamarca. Intersecciones en Antropología, año 1, n 1, pp. 55-78. Facultad de Ciencias Sociales. UNCPBA. Olavaria. Ilustr.

Williams, Verónica I. y Terence N. D'Altroy. 1998. El sur del Tawantinsuyu. Un dominio selectivamente intensivo. Tawantinusyu, 5, pp. 170178. Australian National University. Canberra. Ilustr. 